\title{
Effects of Lifestyle on Urinary 1-hydroxypyrene Concentration
}

\author{
Toshihiro KawAmoto ${ }^{1}$, Mihi Y Ang $^{2}$, Yong-Dae $\mathrm{KIM}^{3}$, Heon $\mathrm{KIM}^{3}$, Tsunehiro Oyama ${ }^{1}$, \\ Toyohi Isse ${ }^{1}$, Koji Matsuno ${ }^{4}$, Takahiko Katoh ${ }^{5}$ and Iwao Uсhіуama ${ }^{6}$
}

${ }^{1}$ Department of Environmental Health, School of Medicine, University of Occupational and Environmental Health, Japan, ${ }^{2}$ Department of Toxicology, College of Pharmacy, Sookmyung Women's University, ${ }^{3}$ Department of Preventive Medicine, College of Medicine, Chunbuk National University, Korea, ${ }^{4}$ Bio-information Research Center, University of Occupational and Environmental Health, ${ }^{5}$ Department of Public Health, Miyazaki University School of Medicine and ${ }^{6}$ Department of Urban and Environmental Engineering, Graduate School of Engineering, Kyoto University, Japan

\begin{abstract}
Effects of Lifestyle on Urinary 1hydroxypyrene Concentration: Toshihiro KаWАMOTо, et al. Department of Environmental Health, School of Medicine, University of Occupational and Environmental Health, Japan-This study aimed to clarify the variation of urinary excretion of 1 hydroxypyrene, which is a major metabolite of pyrene, in relation to lifestyle, including factors such as diet and smoking. The study subjects were 251 workers (male: 196, female: 55, mean age: 44.3) who were not occupationally exposed to PAHs. Urine specimens were collected from 8:00 a.m. to 11:00 a.m. and their 1-hydroxypyrene concentrations were determined by HPLC. A questionnaire was distributed in order to learn gross aspects of the subjects' lifestyles, i.e., smoking, alcohol consumption, coffee/black tea intake, and dietary habits. Multiple linear regression analysis revealed that cigarette consumption most strongly affected the 1-hydroxypyrene level in urine, followed by dietary balance. The urinary 1-hydroxypyrene concentrations of smokers were about 2 times higher than those of non-smokers. Subjects who ate more meat and/or fish excreted 1.5-2 times more 1hydroxypyrene in urine than those who ate more vegetables.
\end{abstract}

(J Occup Health 2007; 49: 183-189)

Key words: 1-Hydroxypyrene, Smoking, PAH (polyaromatic hydrocarbon), Biological monitoring, Biomarkers, Dietary balance, Meat, Vegetable, Fish, Alcohol

Received May 29, 2006; Accepted Feb 14, 2007

Correspondence to: T. КАWАMOTO, Department of Environmental Health, School of Medicine, University of Occupational and Environmental Health, Japan, 1-1 Iseigaoka, Yahatanishi-ku, Kitakyushu807-8555,Japan (e-mail : kawamott@med.uoeh-u.ac.jp)
Urinary 1-hydroxypyrene, a major metabolite of pyrene, is a useful biomarker for assessing exposure to environmental polyaromatic hydrocarbons (PAHs), especially in workers with high occupational exposure, such as workers in coke plants ${ }^{1)}$. However, the use of urinary 1-hydroxypyrene to evaluate individual exposure to air pollution levels of PAHs is problematic. PAHs are taken into our bodies not only from ambient air but also from smoking, food, and other sources. Van Rooji et al. ${ }^{2)}$ estimated the contribution of different sources to daily pyrene intake by distributing a detailed questionnaire to volunteers who were not occupationally exposed to PAHs and reported that the consumption of food products and active smoking accounted for $99 \%$ of total pyrene intake. However, it is not clear how such exposure affects urinary 1-hydroxypyrene levels. Therefore, using a simple questionnaire, we studied the effects of lifestyle factors such as smoking, drinking, dietary habits and coffee/tea consumption on the urinary 1-hydroxypyrene level in a relatively large population who were not occupationally exposed to PAHs.

\section{Methods}

Chemicals

1-Hydroxypyrene was purchased from Aldrich Chemical Co. (Milwaukee, WI). Beta -glucuronidase/ sulfatase (type $\mathrm{H}-2$, from Helix pomatia: $\beta$-glucuronidase activity, 107,200 units/ml and sulfatase activity, 4,500 units $/ \mathrm{m} l$ ) was purchased from Sigma Chemical Co. (St. Louis, MO).

\section{Study subjects}

The study subjects were 251 workers (male: 196, female: 55, mean age: 44.3 , range: $18-71$ ) who lived in Kitakyushu city and its surrounding area. They were not 


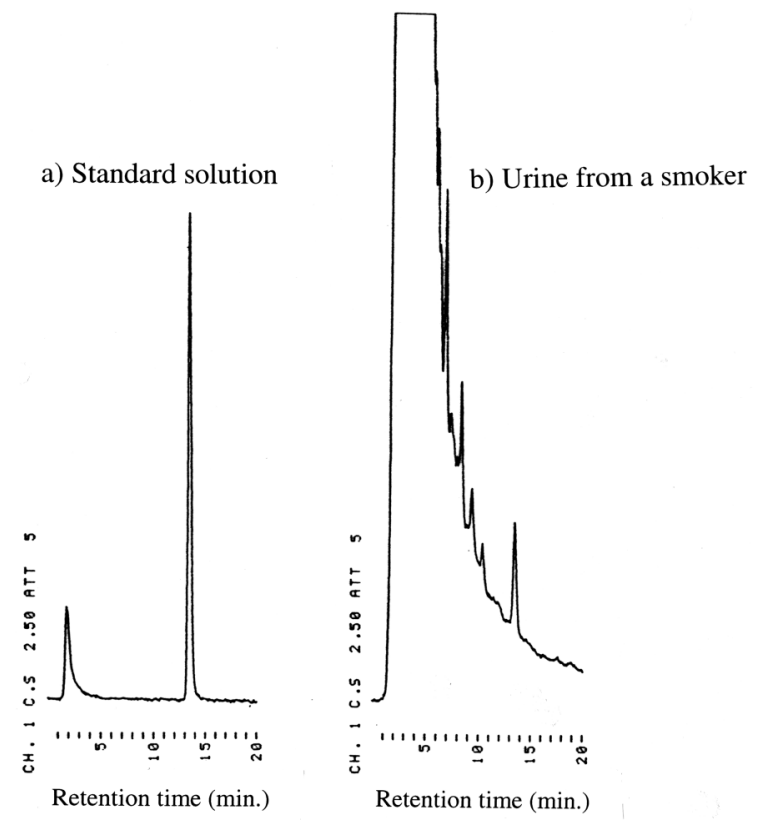

Fig. 1. Chromatograms of a standard solution (a) and a urine sample from a smoker (b). The retention time of 1hydroxypyrene is around $13.5 \mathrm{~min}$.

occupationally exposed to PAHs and gave their informed consent in health examinations. A questionnaire was used to establish gross aspects of lifestyle, i.e., smoking status, alcohol consumption, and intake of coffee or black tea, besides gender and age. Especially, the number of cigarettes smoked within $24 \mathrm{~h}$ before sampling was also asked in the questionnaire. The consumption of greasy or salty food, sweets, fruits, vegetables, meat, and fish was also investigated in order to learn the subjects' dietary habits. This study was approved by the ethics committee of medical care and research of the University of Occupational and Environmental Health.

\section{Measurement of urinary 1-hydroxypyrene}

Urine specimens were collected from 8:00 a.m. to 11:00 a.m. and were stored at $-20^{\circ} \mathrm{C}$ until analysis. The urinary 1-hydroxypyrene concentration was determined by the method described by Taguchi et al. ${ }^{3)}$ with a minor modification. Urine specimens were treated with $\beta$ glucuronidase in sodium acetate buffer ( $\mathrm{pH} \mathrm{5.0)}$ for $12 \mathrm{~h}$, and mixed with acetonitrile. After centrifugation, $100 \mu l$ of the supernatant was subjected to HPLC (Hitachi: L7200 autosampler, L-7100 intelligent, L-7300 column oven) with an L-7480 fluorescence detector and L-7500 chromato integrator. The column was a TOSOH TSK gel ODS- $80^{\mathrm{TM}}$ (reverse phase), and the mobile phase was $65 \%$ acetonitorile and $35 \%$ water. The wavelengths of excitation and emission were $242 \mathrm{~nm}$ and $388 \mathrm{~nm}$, a) Standard solution
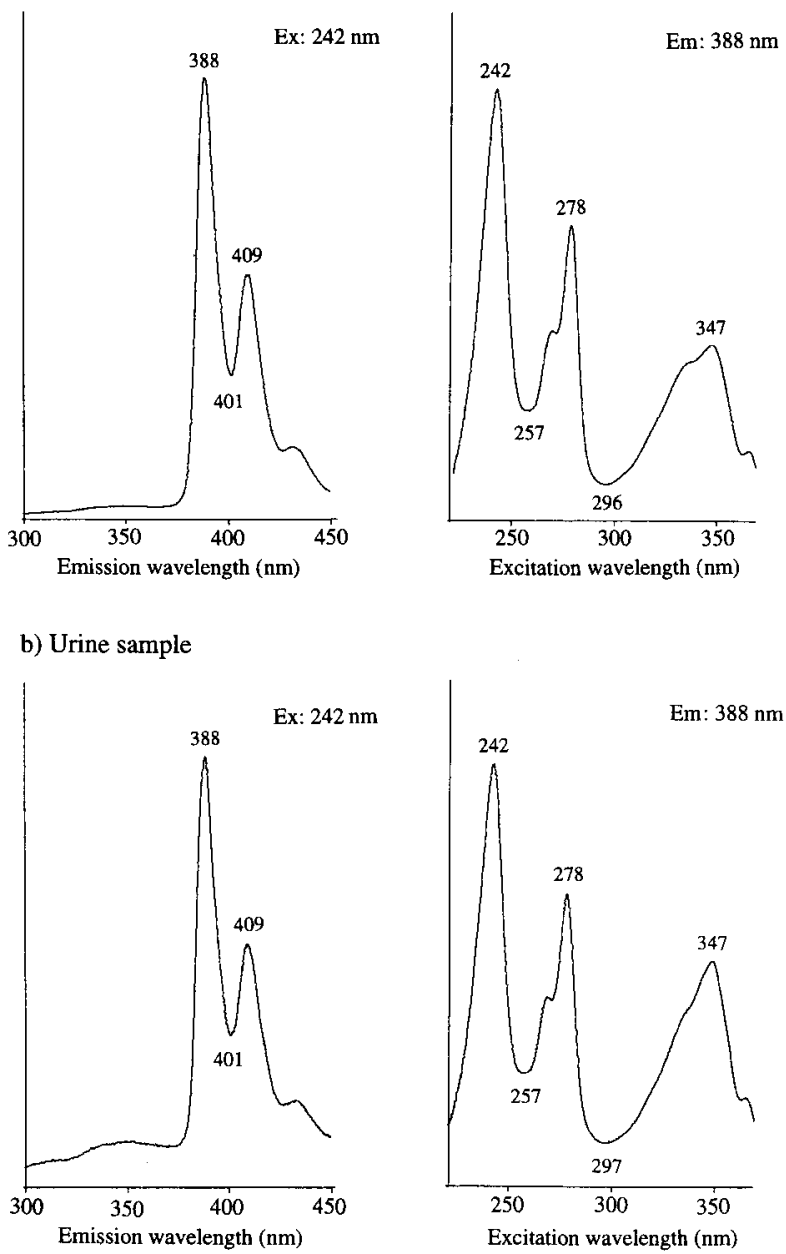

Fig. 2. Emission wavelength scan with excitation at $242 \mathrm{~nm}$, and excitation wavelength scan with emission at 388 $\mathrm{nm}$ of the HPLC peak of the standard solution (a) and of the HPLC sample fraction with the same retention time from the urine sample (b).

respectively.

\section{Statistical analysis}

Lifestyle data were quantified as shown in Table 1. Two dummy variables, $\mathrm{X} 1$ and $\mathrm{X} 2$, are created to index three categories of dietary balance. Multiple linear regression analysis was applied to investigate the effect of lifestyle in determining the urinary levels of logtransformed 1-hydroxypyrene. Two-way ANOVA was also carried out to compare dietary effects. Multiple comparisons were done by Fisher's PLDS with one way ANOVA.

\section{Results}

Simple 1-hydroxypyrene analysis

Figure 1 shows chromatograms of a standard sample 

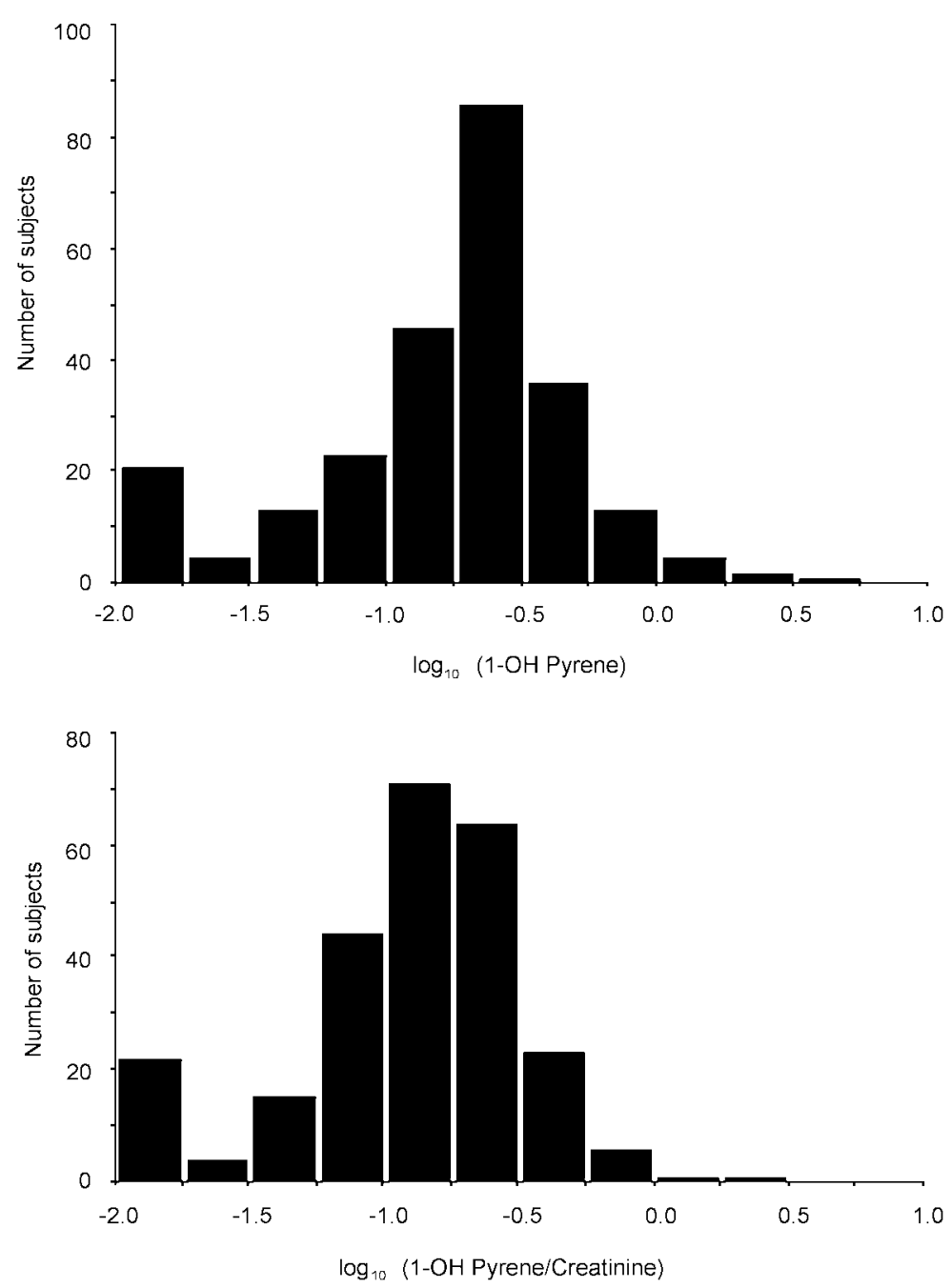

Fig. 3. Distribution of urinary 1-hydroxypyrene concentrations after logtransformation.

and a urine sample from a smoker. The emission and excitation wavelength scans of the HPLC peak of the standard sample and the HPLC fraction with the same retention time from the urine sample were identical (Fig. 2). The detection limit was $0.02 \mu \mathrm{g} / l$. The samples with measurement results below the detection limit were assigned a value of half of the detection limit. As the distribution of urinary 1-hydroxypyrene levels was almost logarithmically normal both with and without creatinine correction (Fig. 3), statistical analyses were carried out after log-transformation. The between-day relative standard deviation (CV) was $10.7 \%$ at $1.0 \mu \mathrm{g} / \mathrm{l}$.

Photodegradation of 1-hydroxypyrene was studied by exposing the 1-hydroxypyrene solution to artificial light (fluorescent lamp) in an experimental room (Fig. 4). The 1-hydroxypyrene concentration was reduced exponentially over time with a half-life of approximately

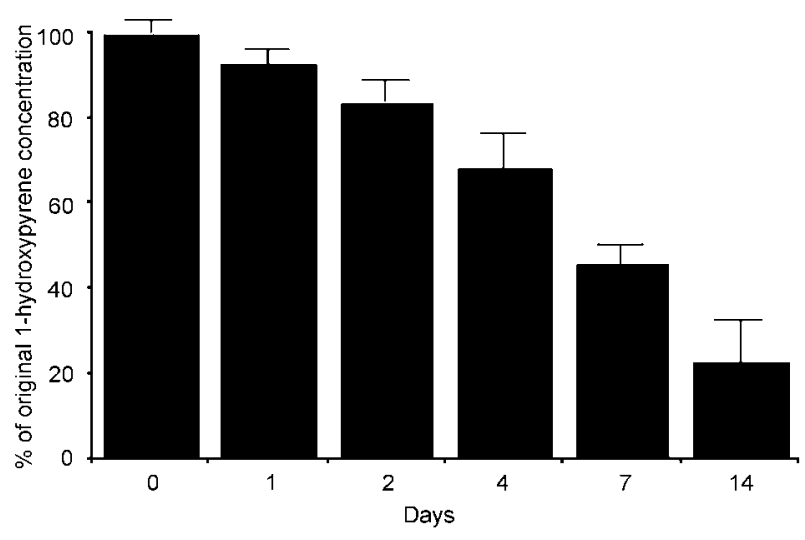

Fig. 4. Photodegradation of 1-hydroxypyrene $(2 \mathrm{ng} / \mathrm{ml}$ in $50 \%$ acetonitrile) on an experimental bench under artificial light under the usual sample handling conditions. 
Table 1. Quantification of gender and lifestyle data, and characteristics of subjects

\begin{tabular}{|c|c|c|}
\hline Variable & Quantification & Number of Subjects \\
\hline \multirow[t]{2}{*}{ Gender } & Male $=0$ & 196 \\
\hline & Female $=1$ & 55 \\
\hline Age & Age & 251 \\
\hline \multirow[t]{2}{*}{ Smoking } & Non-smoker $=0$ & 137 \\
\hline & Smoker=Number of cigarettes smoked within $24 \mathrm{~h}$ & 114 \\
\hline \multirow[t]{4}{*}{ Coffee and tea } & Usually not taken $=0$ & 39 \\
\hline & $0-1 \mathrm{cup} / \mathrm{d}=1$ & 49 \\
\hline & $1-2$ cups/d=2 & 117 \\
\hline & $>3$ cups $/ \mathrm{d}=3$ & 46 \\
\hline \multirow[t]{4}{*}{ Alcohol consumption } & Non-drinker $=0$ & 78 \\
\hline & $0-1 \mathrm{~d} / \mathrm{wk}=1$ & 53 \\
\hline & $2-4 \mathrm{~d} / \mathrm{wk}=2$ & 40 \\
\hline & $>5 \mathrm{~d} / \mathrm{wk}=3$ & 80 \\
\hline \multicolumn{3}{|l|}{ Dietary balance } \\
\hline \multirow{2}{*}{ Dummy valuable (X1) } & Eats more vegetables $=0$; Eats more meat or fish $=0$ & 85 \\
\hline & Eats meat or fish, and vegetables in moderate proportions $=1$ & 166 \\
\hline \multirow[t]{2}{*}{ Dummy valuable (X2) } & $\begin{array}{l}\text { Eats more vegetables }=0 \text {; Eats meat or fish, and vegetables in } \\
\text { moderate proportions }=0\end{array}$ & 224 \\
\hline & Eats more meat or fish $=1$ & 27 \\
\hline \multirow[t]{2}{*}{ Greasy food } & Does not consume large amounts of greasy foods $=0$ & 117 \\
\hline & Consumes large amounts of greasy foods $=1$ & 134 \\
\hline \multirow[t]{2}{*}{ Salt } & Does not eat salty foods $=0$ & 112 \\
\hline & Eats salty foods $=1$ & 139 \\
\hline \multirow[t]{2}{*}{ Sweets and fruits } & Seldom eats $=0$ & 130 \\
\hline & Frequently eats $=1$ & 121 \\
\hline
\end{tabular}

$7 \mathrm{~d}$. Although the half-life of 1-hydroxypyrene photodegradation would vary according to the intensity of the room light, the treatment of urine samples for analysis is not likely to cause a significant decrease of the 1-hydroxypyrene level except for the step of overnight enzymatic digestion. Therefore, only the incubation with $\beta$-glucuronidase was done in the dark.

Effects of lifestyle on concentration of urinary 1 hydroxypyrene

Table 1 shows the characteristics of the subjects. Multiple linear regression analysis of lifestyle factors and urinary 1-hydroxypyrene levels revealed that cigarette smoking and dietary balance (dummy valuable X2; whether more meat and/or fish, or more vegetables were consumed) were significantly related to the urinary 1hydroxypyrene concentration (Table 2). The great majority of the variance was found to be due to cigarette smoking. Urinary 1-hydroxypyrene levels according to smoking status and dietary balance are shown in Table 3 . The urinary 1-hydroxypyrene concentration of smokers was about 2 times higher than that of non-smokers $(p<0.001)$. Subjects who ate more meat and/or fish excreted 1.5-2 times more 1-hydroxypyrene in urine than those who ate more vegetables $(p<0.05)$.

\section{Discussion}

In this study, the 1-hydroxypyrene concentration in urine was analyzed by the method described by Taguchi et al. ${ }^{3)}$ with a minor modification. In most reports, 1hydroxypyrene has been measured using the method developed by Jongeneelen ${ }^{4}$, in which the samples are cleaned using a Sep Column and concentrated by evaporation. Compared to that method, our method is simpler, and is more convenient for analyzing a large number of samples in an epidemiological study because of its simplicity. Its reproducibility is also good because pretreatment consists of only one step (glucuronidase treatment). The detection limit of this method did not cause severe problems in analyzing the 1-hydroxypyrene levels of the subjects in the present study. The percentage of samples with 1-hydroxypyrene levels under the detection limit was only $8 \%$ (21 out of 251 samples). Therefore, we consider that this method is useful for the measurement of urinary 1-hydroxypyrene levels from subjects exposed to ambient air.

In the present study, the urinary 1-hydroxypyrene concentration of smokers was 0.170 (2.67) $\mu \mathrm{g} / \mathrm{g}$ creatinine 
Table 2. Multiple linear regression analysis of lifestyle factors in determining urinary concentration of log-transformed 1hydroxypyrene

\begin{tabular}{|c|c|c|c|c|c|c|c|c|}
\hline & \multicolumn{4}{|c|}{ Log(1-OHpyrene $)^{\mathrm{a}}$} & \multicolumn{4}{|c|}{$\log (1-O H p y r e n e / C)^{b}$} \\
\hline & $\begin{array}{l}\text { Regression } \\
\text { Coefficient }\end{array}$ & $\begin{array}{c}\text { Standard } \\
\text { Error }\end{array}$ & $\begin{array}{c}\text { Standard } \\
\text { Regression } \\
\text { Coefficient }\end{array}$ & $p$-Value & $\begin{array}{l}\text { Regression } \\
\text { Coefficient }\end{array}$ & $\begin{array}{c}\text { Standard } \\
\text { Error }\end{array}$ & $\begin{array}{c}\text { Standard } \\
\text { Regression } \\
\text { Coefficient }\end{array}$ & $p$-Value \\
\hline Gender & -0.087 & 0.084 & -0.072 & 0.297 & 0.001 & 0.074 & 0.001 & 0.985 \\
\hline Age & -0.000 & 0.003 & 0.003 & 0.962 & 0.004 & 0.003 & 0.101 & 0.118 \\
\hline No. of cigarettes & 0.014 & 0.003 & 0.314 & $<0.001 * *$ & 0.013 & 0.003 & 0.346 & $<0.001 * *$ \\
\hline Coffee and tea & 0.020 & 0.035 & 0.038 & 0.562 & 0.028 & 0.031 & 0.059 & 0.359 \\
\hline Alcohol & -0.003 & 0.029 & -0.008 & 0.916 & 0.011 & 0.026 & 0.029 & 0.685 \\
\hline Dietary balance (X1) & 0.163 & 0.101 & 0.152 & 0.106 & 0.114 & 0.089 & 0.119 & 0.202 \\
\hline Dietary balance (X2) & 0.264 & 0.113 & 0.221 & $0.021 *$ & 0.226 & 0.100 & 0.212 & $0.025^{*}$ \\
\hline Greasy food & 0.024 & 0.064 & 0.023 & 0.711 & -0.034 & 0.056 & -0.037 & 0.543 \\
\hline Salt & -0.001 & 0.064 & -0.001 & 0.990 & 0.005 & 0.056 & 0.006 & 0.928 \\
\hline Sweets and fruits & -0.026 & 0.067 & -0.025 & 0.698 & -0.072 & 0.059 & -0.078 & 0.226 \\
\hline Intercept & -1.116 & 0.213 & -1.116 & $<0.001$ & -1.388 & 0.188 & -1.388 & $<0.001$ \\
\hline $\begin{array}{l}\mathrm{R} \text {-square } \\
p \text {-value }\end{array}$ & $\begin{array}{r}0.155 \\
<0.001\end{array}$ & & & & $\begin{array}{r}0.172 \\
<0.001\end{array}$ & & & \\
\hline
\end{tabular}

aLogarithm of 1-OHpyrene ( $\mu \mathrm{g} / l)$, bLogarithm of 1-OHpyrene/creatinine ( $\mu \mathrm{g} / \mathrm{g}$ creatinine). $* p<0.05 ; * * p<0.001$.

Table 3. The effects of smoking and dietary balance on urinary 1-hydroxypyrene concentration

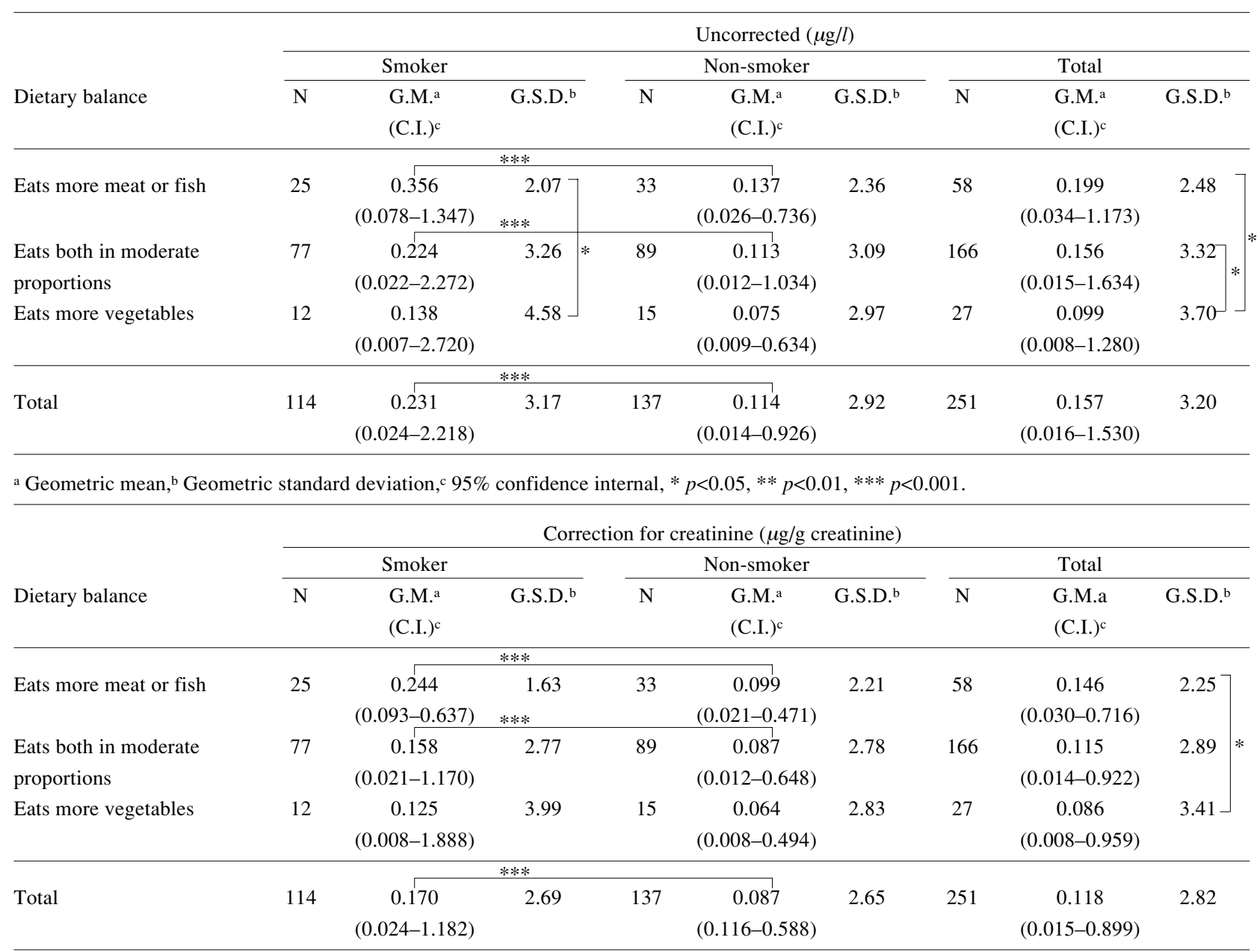

${ }^{\mathrm{a} G e o m e t r i c ~ m e a n, ~}{ }^{\mathrm{b} G e o m e t r i c ~ s t a n d a r d ~ d e v i a t i o n, ~}{ }^{\mathrm{c}} 95 \%$ confidence internal, ${ }^{*} p<0.05,{ }^{*} p<0.01,{ }^{* * *} p<0.001$. 
$(0.088 \mu \mathrm{mol} / \mathrm{mol}$ creatinine $)$, and that of non-smokers was $0.087(2.65) \mu \mathrm{g} / \mathrm{g}$ creatinine $(0.045 \mu \mathrm{mol} / \mathrm{mol}$ creatinine $)$, expressed as geometric means (geometric standard deviations). These urinary 1-hydroxypyrene levels in Japanese are very similar to the Korean levels reported in our previous studies, that is, 0.04 (1.81) $\mu \mathrm{mol} / \mathrm{mol}$ creatinine in smokers and $0.03(1.71) \mu \mathrm{mol} / \mathrm{mol}$ creatinine in non-smokers among male university students ${ }^{5)}$, and $0.025 \mu \mathrm{mol} / \mathrm{mol}$ creatinine in Korean people (age: 36.5 +/- 11.1 yr, male: $63.3 \%$, smokers: $38.9 \%$ ) who were not occupationally exposed to $\mathrm{PAHs}^{6}$.

Van Rooji et al. $^{2)}$ reported that smokers excreted on average 0.25 (range; $0.17-0.76) \mu \mathrm{mol} / \mathrm{mol}$ creatinine and non-smokers on average $0.12(0.08-0.68) \mu \mathrm{mol} / \mathrm{mol}$ creatinine in a study examining 76 Dutch male volunteers. In smoking and non-smoking German housewives, the medians of urinary 1-hydroxyprene were $0.25 \mu \mathrm{mol} / \mathrm{mol}$ creatinine and $0.08 \mu \mathrm{mol} / \mathrm{mol}$ creatinine, respectively ${ }^{7)}$. Van Rooji et $a l .^{2)}$ also reviewed earlier studies and concluded that the median baseline 1-hydroxypyrene concentrations in the urine of male smokers and nonsmokers were $0.17-0.76 \mu \mathrm{mol} / \mathrm{mol}$ creatinine and $0.08-$ $0.68 \mu \mathrm{mol} / \mathrm{mol}$ creatinine, respectively. These values are higher that those in Japanese and Koreans. The effect of the analytical methods on the measurement results is not clear at the present time. However, van Rooji et al. reviewed data obtained in the Netherlands, Turkey, China, Denmark and Belgium. As Japanese and Korean people eat less meat compared to these other nationalities, the difference in baseline 1-hydroxypyrene levels might have been caused by differences in dietary habits.

The present study confirms the findings of earlier studies $^{6,8)}$ that the smoking of cigarettes significantly increases the urinary 1-hydroxypyrene concentration, while alcohol consumption does not affect the urinary 1hydroxypyrene concentration.

The relative contribution of different sources to daily pyrene intake has been estimated in human volunteers who were not occupationally exposed to $\mathrm{PAHs}^{2)}$. Mainstream smoking and foods containing PAHs accounted for some $99 \%$ of the total pyrene intake, while the contributions of ETS and indoor/outdoor ambient air were insignificant. The variation of the level of urinary 1-hydroxypyrene explained by smoking and foods was $66 \%$ and $2 \%$, respectively.

In the present study, the urinary 1-hydroxypyrene level was affected mainly by cigarette smoking. Dietary balance, that is, the ratio of meat/fish to vegetables, was also related to these levels. In the present study, we asked subjects 4 questions concerning dietary habits, i.e. dietary balance, greasy food, salt and sweet/fruits. There were no criteria for how the subjects should answer: they answered these questions as they felt appropriate. However, it is surprising that urinary 1-hydroxypyrene levels differed by 2-3 times among people with different dietary habits which were classified according to a very simple question, that is, dietary balance.

The urinary concentrations of some metabolites other than 1-hydroxypyrene are also affected by lifestyle. The background level of urinary hippuric acid is reduced by alcohol consumption. The urinary phenol concentration is reduced by coffee and tea intake, and the $o$-cresol concentration is increased with the number of cigarettes smoked $^{9)}$. However, dietary habits, for example, dietary balance and the intake of greasy food, salt, sweets and fruits, are not related to the urinary background levels of hippuric acid, phenol, or $o$ - or $p$-cresols.

1-Hydroxypyrene is formed from pyrene by reactions catalyzed by cytochrome P450s. We have studied the 1hydroxylation of pyrene by 10 isoforms of human cytochrome P450s expressed from cloned $\mathrm{cDNAs}^{10)}$. CYP1A1 exhibited the highest activity at both 0.5 and $50 \mu \mathrm{M}$ pyrene, followed by CYP1B1 and $1 \mathrm{~A} 2$, whereas other isoforms, including CYP2A6, 2C8, 2C9*1, 2C19, 2D6, $2 \mathrm{E} 1$ and $3 \mathrm{~A} 4$, showed very low or undetectable rates of 1-hydroxylation.

CYP1A1 is reported to have polymorphic sites in exon 7 and in the 3'-flanking region. An isoleucine-valine transition caused by a point mutation in exon $7^{11)}$ has been found to cosegregate with a point mutation in the 3'-flanking region, which causes the generation of an MspI restriction site. It is suspected that CYP1A1 polymorphism causes changes in monooxygenation activity that alter the rate of formation of 1-hydroxyprene from pyrene. Recently, a relationship between CYP1A1 polymorphism and urinary 1-hydroxypyrene levels has been reported. Wu et al. ${ }^{12)}$ showed a significant increase in urinary 1-hydroxypyrene excretion in coke-oven workers with the CYP1A1 MspI homozygous variant genotype. Merlo et al. ${ }^{13)}$ studied the urinary excretion of 1-hydroxypyrene in 94 traffic police officers and 52 control subjects exposed to indoor air pollution. No significant role of any metabolic polymorphism of CYP1A1 (MspI) was detected. Our recent studies ${ }^{6,8)}$ showed no differences in urinary 1-hydroxypyrene levels according to CYP1A1 polymorphism, either. One reason why the results are inconsistent even after the adjustment for smoking and occupational exposure may be that the differences of 1-hydroxypyrene formation from pyrene due to CYP1A1 polymorphism are concealed by the wide variation of pyrene intake from various sources such as dietary intake.

In conclusion, we clarified that the urinary 1hydroxypyrene level was strongly affected by smoking. It is also noteworthy that the answer to the simple question of whether subjects eat more meat and fish or more vegetables may also be a good indicator for predicting urinary 1-hydroxypyrene levels of subjects who are not exposed to PAHs occupationally. 
Acknowledgments: Part of this study was supported by a Grant-in-Aid for Scientific Research (C) (2) (07670416) from the Japanese Society for the Promotion of Science (JSPS), Joint Research Projects and Scientific Seminar from JSPS, and Health and Labour and Welfare Research Grants of the Ministry of Health, Labour and Welfare (Studies on biomonitoring levels of trace indoor pollutant chemicals and health).

\section{References}

1) Jongeneelen FJ, van Leewen FE, Oosterink S, Anzion RBM, van der Loop F, Bos RP and van Veen HG: Ambient and biological monitoring of coke oven workers, determinants of the internal dose of polycyclic aromatic hydrocarbons. Br J Ind Med 47, 454-461 (1990)

2) van Rooji JGM, Veeger MMS, Bodelier-Bade MM, Scheepers PTJ and Jongeneelen FJ: Smoking and dietary intake of polycyclic aromatic hydrocarbons as sources of interindividual variability in the base line excretion of 1-hydroxypyrene in urine. Int Arch Occup Environ Health 66, 55-65 (1994)

3) Taguchi T, Horike T and Ogata M: Micro determination of urinary 1-pyrenol by high performance liquid chromatography. Medicine and Biology 127, 201-205 (1993) (in Japanese)

4) Jongeneelen FJ, Anzion RBM and Henderson PT: Determination of hydroxylated metabolites of polycyclic aromatic hydrocarbons in urine. $\mathrm{J}$ Chromatogr 413, 227-232 (1987)

5) Kim H, Cho SH, Kang JW, Kim YD, Nan HM, Lee $\mathrm{CH}$, Lee $\mathrm{H}$ and Kawamoto T: Urinary 1-hydroxypyrene and 2-naphthol concentrations in male Koreans. Int Arch Occup Environ Health 74, 59-62 (2001)

6) Yang M, Jang JY, Kim S, Lee SM, Chang SS, Cheong HK, Lee E, Kang D, Kim H, Kawamoto T and Shin HD: Genetic effects on urinary 1-hydroxypyrene levels in Korean population. Carcinogenesis 24, 1085-1089
(2003)

7) Guendel J, Mannschreck C, Buttner K, Ewers U and Angerer J: Rinary levels of 1-hydorxypyrene, 1-, 2-, 3 -, and 4-hydroxyphenanthrene in females living in an indusrial area of Germany. Arch Environ Contam Toxicol 31, 585-590 (1996)

8) Nan HM, Kim H, Lim HS, Choi JK, Kawamoto T, Kang JW, Lee CH, Kim YD and Kwon EH: Effects of occupation, lifestyle and genetic polymorphisms of CYP1A1, CYP2E1, GSTM1 and GSTT1 on urinary 1-hydroxypyrene and 2-naphthol concentrations. Carcinogenesis 22, 787-793 (2001)

9) Kawamoto T, Koga M, Oyama T and Kodama Y: Habitual and genetic factors that affect urinary background levels of biomarkers for organic solvent exposure. Arch Environ Contam Toxicol 30, 114-120 (1996)

10) Kim YD, Todoroki H, Oyama T, Isse T, Matsumoto A, Yamaguchi T, Kim H, Uchiyama I and Kawamoto T: Identification of cytochrome P450 isoform involved in 1-hydroxylation of pyrene. Environ Res 94, 262 266 (2004)

11) Oyama $T$, Mitsudomi $T$, Kawamoto $T$, Ogami A, Osaki T, Kodama Y and Yasumoto K: Detection of CYP1A1 gene polymorphism using designed RFLP and distributions of CYP1A1 genotypes in Japanese. Int Arch Occup Environ Health 67, 253-256 (1995)

12) Wu MT, Huang SL, Ho CK, Yeh YF and Christiani DC: Cytochrome P450 1A1 MspI polymorphism and urinary 1-hydroxypyrene concentrations in Coke-Oven Workers. Cancer Epidemiol Biomark Prev 7, 823-829 (1998)

13) Melro F, Andreassen A, Weston A, Pan CF, Haugen A, Valerio F, Reggiardo G, Fontana V, Garte S, Puntoni R and Abbondandolo A: Urinary excretion of 1hydroxypyrene as a marker for exposure to urban air levels of polycyclic aromatic hydrocarbons. Cancer Epidemiol Biomark Prev 7, 147-155 (1998) 